\title{
Jornada mundial de la paz "Un compromiso siempre actual: educar para la paz"
}

El mensaje del Papa Juan Pablo II presenta dos novedades. En anexo bibliográfico reproduce los títulos de los mensajes de las 37 jomadas mundiales de la paz que, desde 1968, los sucesivos papas han dirigido a todos los hombres de buena voluntad. El mensaje de este año 2004 sería el 38. Este largo listado es un positivo aporte a "la cultura de la paz". En cada título se entremezclan los obstáculos y los caminos para alcanzar la Pacem in terris del beato Juan XXIII o el ser "hacedores de la paz" de Juan Pablo II, en su primera visita a El Salvador. La segunda novedad es el cuarto grupo de destinatarios de este mensaje, el cual además de a los jefes de las naciones, que tienen el deber de promover la paz, a los juristas, que deben abrir caminos de entendimiento pacífico, preparando convenciones y tratados que refuerzan la legalidad internacional, a los educadores de la juventud, que deben formar las conciencias en el camino de la comprensión y el diálogo, y a, aquí está la novedad, "ustedes hombres y mujeres que sienten la tentación de recurrir al terrorismo como instrumento inaceptable, comprometiendo así, desde la raíz, la causa por la cual están combatiendo".

\section{La plaga del terrorismo}

Al decir el Papa "me dirijo también a ustedes", está indicando que no son "ellos" los únicos destinatarios del mensaje ni tampoco son "ellos" los únicos obstáculos a la paz mundial. Podríamos co- meter un serio error al reducir el llamado del Papa a uno solo de los cuatro destinatarios del mensaje. Pero, al mismo tiempo, está indicando que, si bien el terrorismo no es un flagelo que aparece con el tercer milenio, sí ha cobrado mayor amplitud $\mathrm{e}$ intensidad mundial. No hay duda que, bajo diversas modalidades, vivimos en un mundo atemorizado. También hay que decir que la cruzada contra el terrorismo sería más honesta y más cristiana si los grandes medios de comunicación social no restringieran su concepto de terrorismo solo a las acciones violentas contra los ciudadanos del norte o contra las fuerzas ocupantes, como si un uniforme militar justificara cualquier tipo de acción. Esta moral parcial no está de acuerdo con el jus gentium (el derecho de gentes), que se menciona más adelante. El Papa enfrenta un problema tan importante y tan real como delicado: ¿qué es terrorismo y quiénes son terroristas en el mundo de hoy? Juan Pablo II habla de "La plaga funesta del terrorismo. La plaga del terrorismo se ha hecho más virulenta en estos últimos años y ha producido masacres atroces que han obstaculizado cada vez más el proceso de diálogo y la negociación, exacerbando los ánimos y agravando los problemas, especialmente en Oriente Medio".

El Papa afirma que estas situaciones conflictivas derivan de los cambios del panorama mundial contemporáneo, que sus protagonistas son entes derivados de la disgregación de los estados o están 
vinculados a reivindicaciones independentistas, o bien están relacionados con aguerridas organizaciones criminales. Parecería que una causa compleja -cambios en el panorama mundial y disgregación de los estados - genera una diversificación de motivos y de acciones terroristas. El fenómeno del terorismo no es uniforme ni en sus causas ni en sus modos de lucha. A modo de ejemplo, los chechenos en Rusia, ¿son terroristas o son independentistas, o son las dos cosas a la vez? No siempre es fácil dar la respuesta exacta.

Párrafo seguido, el Papa trata de especificar un poco más las causas y las respuestas adecuadas. "La lucha contra el terrorismo no puede reducirse solo a operaciones represivas y punitivas. Es esencial que incluso el recurso necesario a la fuerza vaya acompañado por un análisis lúcido de los motivos subyacentes a los ataques terroristas [...] evitando las causas que originan las situaciones de injusticia de las cuales surgen a menudo los móviles de los actos más desesperados y sanguinarios". El Papa agrega, "En todo caso, los gobiemos democráticos saben bien que el uso de la fuerza contra los terroristas no puede justificar la renuncia a los principios de un Estado de derecho [...] dado que el fin no justifica los medios" (N. 8). En el origen del terrorismo suelen existir "situaciones de injusticia" y, en la réplica al terrorismo, surgen nuevas formas de terrorismo, incluso un terrorismo de Estado.

En tres ocasiones, Juan Pablo II hace mención especial del Medio Oriente y Palestina. Sin embargo, en este breve mensaje, no pone nombres ni apellidos, ¿quiénes son los terroristas y quiénes son los aterrorizados? Implícitamente dijo algo más en febrero y marzo de 2003. "Pido a todos los hombres de buena voluntad que destierren toda forma de intolerancia y discriminación. Hagan lo posible para construir la paz, sobre todo en Tierra Santa para detener la inútil espiral de violencia ciega, y en el Medio Oriente para detener la siniestra obcecación de un confliclo que, gracias al compromiso de todos, puede evitarse. ¿Qué decir de la amenaza de una guerra que podría golpear al pueblo de Irak, la tierra de los profetas, pueblo que ya ha sido tratado con severidad por más de doce años de embargo?". Cuando el 16 de marzo, "las fuerzas de la coalición", sin autorización del Consejo de Seguridad, decidieron iniciar la "guerra preventiva" contra Irak, Juan Pablo II elevó su voz: "Quien decida que todos los medios de los que dispone el derecho internacional se han agotado, tendrá que asumir una grave responsabilidad ante Dios, ante su propia conciencia y ante la historia".

La referencia de Juan Pablo II a Irak como la tierra de los profetas recuerda que este conflicto adquiere un carácter peculiar, muy peligroso. El mandatario que decidió iniciar esta guerra dijo que la posible campaña militar es "contra los hombres $\sin$ fe y $\sin$ ley. Mi fe me sostiene, porque oro cada día. Pido que ella me guíe y me dé sabiduría y fuerza". Esta repetida invocación a Dios ha transformado - a los ojos de millones de musulmanes- un conflicto militar en una "nueva cruzada o guerra santa", en un choque de religiones y civilizaciones. La clave religiosa forma simbiosis con el ideal nacionalista. Los invasores de la tierra árabe son infieles y las personas que inmolan su vida, realizan un sacrificio religioso. Al pretender cubrir con el velo de la fe una campaña motivada por objetivos económicos, se recrudece la resistencia violenta y se hace más difícil el logro de la paz en el Medio Oriente. Algo similar sucede en Tierra Santa.

Seríamos injustos con la historia si restringimos nuestra definición de terrorismo a los ataques moral y humanamente condenables del 11 de septiembre. No se pueden sacrificar vidas humanas, en aras de una ideología religiosa, política, económica y étnica. "El fin no justifica los medios". Esta ley natural se aplica por igual, tanto al terrorismo de grupos criminales como al terrorismo de Estado. Recordamos todavía las palabras de M. Gorbachov: "Las víctimas de los atentados del 11 de septiembre en Estados Unidos no habrían muerto en vano si el mundo aprovecha la ocasión para mirarse en el espejo y establecer un compromiso moral sin caer en el pánico". Parece que ha sido más bien el pánico que la moral lo que ha inspirado las políticas de "la seguridad duradera" del hemisferio norte. Testimonio de ello es el "pacto OTAN-Rusia", firmado en Roma, en mayo de 2002. "La guerra fría ha terminado". Rusia no es el enemigo de la humanidad. "Vivimos en un mundo nuevo [...] donde nuevas amenazas y desafíos exigen respuestas cada vez más unidas. Por esta razón, los estados miembros de la OTAN y la Federación de Rusia abrimos un nuevo capítulo en nuestras relaciones". Se pacta la "seguridad duradera", por la vía armada contra el terrorismo, que ha generado un "nacional integrismo", es decir, la xenofobia y el rechazo del extranjero. Conviene escuchar a la otra parte. "Muchos musulmanes piensan que su religión se ha diabolizado; el oeste ve al mundo islá- 
mico como inestable, hostil y proclive a atacar a occidente. El choque de civilizaciones es una mascarada. Se necesita una modemización ilustrada". Esto se dijo en la reciente cumbre de Naciones Unidas (Le Monde, 25 de septiembre de 2003).

Tampoco podemos admitir que este terrorismo, en concreto, sea el "problema número uno" del mundo. En la cumbre de Naciones Unidas, el 10 de noviembre de 2001, el presidente Bush urgió a la organización a sumarse a la batalla contra el terrorismo. "Toda una generación tiene hoy el deber de acabar para siempre con una amenaza planetaria. Quien no se sume a esta lucha 'pagará las consecuencias"' (EI País, 11 de noviembre de 2001). Al Secretario General le tocó cuestionar este unilateralismo. "Estamos tentados de concentrar todas nuestras energías en la lucha contra el terrorismo, pero esto sería conceder la victoria a los terroristas, porque los problemas a que nos habiamos enfrentado el 10 de septiembre (Cumbre del Milenio, 2000) no han cambiado, sino que se hacen más urgentes. Para evitar un enfrentamiento mutuamente destructivo entre civilizaciones, es necesario dar una esperanza real a millones de personas acuciadas por la pobreza, los conflictos y las enfermedades" (Le Monde, 10 de noviembre de 2001).

\section{Las amenazas duras y las amenazas blandas}

Como el Papa menciona varias veces a Naciones Unidas, al hablar del nuevo ordenamiento mundial, cabe aquí una breve referencia a dos de sus cumbres, donde el problema del terrorismo se presenta en un sentido amplio. En la cumbre del Milenio (Nueva York, septiembre de 2000), el Secretario General dijo, en su discurso inaugural, "Afrontamos desafíos mundiales que nos obligan a trabajar juntos, y si esto es cierto en la esfera económica, lo es aún más ante el desafío que representan las matanzas y las guerras". K. Annan recuerda cómo el Consejo de Seguridad (los cinco grandes) se cruzaron de brazos cuando Boutros Ghali pidió enviar cascos azules para detener las matanzas en Bosnia-Herzegobina, en 1992, y luego los genocidios en Ruanda, Sierra Leona y Timor Oriental. "Todos desoyeron a Boutros Ghali cuando solicitó una policía internacional, en 1996, para separar asesinos de víctimas, en los campos de refugiados en Zaire. ¿El resultado? La actual guerra de Congo-Kinzasa".

Frente a estos condenables descuidos, Annan cuestionó la solidaridad humana, cuando ésta se convierte en anarquía mundial. "El instinto de solidaridad humana - que impulsa a algunos estados a acudir en ayuda de los ciudadanos de otros estados o a presentar cargos contra sus antiguos dictadores - es digno de alabanza. Pero cuando estas acciones las aplican uno o pocos estados, en nombre de su propia autoridad, traen consigo el riesgo de la anarquía mundial". Clara alusión a la guerra que Estados Unidos y la OTAN lanzaron contra Serbia-Kosovo, sin autorización del Consejo de Seguridad. Por ello, el Secretario General urge a todos los estados a ratificar los estatutos de la Corte Penal Intemacional, "que juzgue a los genocidas que tribunales nacionales no pueden o no quieren juzgar". Juan Pablo II avaló esta petición, en su mensaje de la paz de 1999. "Un signo positivo es la reciente iniciativa de una conferencia diplomática de Naciones Unidas, en 1998, que, con una deliberación específica, ha aprobado los estatutos de una Corte Penal Internacional, destinada a determinar las culpas y castigar a los responsables de los crímenes de genocidio, crímenes contra la humanidad, crímenes de guerra y de agresión" (N. 7). Solo cinco de los quince miembros del actual Consejo de Seguridad han ratificado estos estatutos. ¿Qué seguridad nos puede dar este Consejo de Seguridad?

En su discurso a la 58. Asamblea de Naciones Unidas, el 23 septiembre de 2003, el tema central del informe del Secretario General, sobre el estado de la comunidad intemacional, fue el sistema de seguridad colectiva, heredada de la segunda guerra mundial. En él, Annan se pregunta, ¿cómo podrá funcionar esa seguridad, si las diferentes regiones del mundo no tienen la misma percepción de qué es hoy lo que las amenaza? "Tenemos que enfrentar nuevas amenazas: las nuevas formas de terrorismo, la proliferación de armas de destrucción masiva. Pero, mientras que para algunos es evidente que estas amenazas son el desafío mayor a la paz mundial y a la seguridad, otros se sienten directamente más amenazados por pequeñas ammas, en sus conflictos civiles, o por lo que se denominan 'amenazas blandas', como la persistencia de la extrema pobreza, la disparidad de ingresos dentro y entre sociedades, la difusión de enfermedades infecciosas, el cambio climático y el deterioro ambiental. Con franqueza, si se hiciera un sondeo, en todas las regiones del mundo, no estoy seguro de que las armas de destrucción masiva o el terrorismo aparezcan en primer lugar. En realidad, no podemos escoger. Naciones Unidas tiene que enfrentar todos los desafíos, los nuevos y los antiguos, 
las amenazas duras y las amenazas blandas" ( $L e$ Monde, 23 de septiembre de 2003).

En su discurso, el Secretario General cuestiona la guerra preventiva, defendida por el gobiemo de Estados Unidos. "El Artículo 51 (de la Carta de Naciones Unidas) prevé que todos los estados, si son atacados, tienen el derecho a defenderse. Hasta ahora estaba admitido que cuando los estados se extralimitan y deciden recurrir a la fuerza para responder a graves amenazas a la seguridad y a la paz internacional, necesitan contar con la legitimidad que solo puede procurar Naciones Unidas. Ahora, algunos dicen que esta teoría no es sostenible, cuando un ataque armado puede lanzarse en cualquier momento, sin previo aviso o por un grupo clandestino. Los estados arguyen que tienen el derecho y la obligación de utilizar la fuerza de manera preventiva, incluso sobre el territorio de otros estados y aun cuando los sistemas de armas utilizables en el ataque estén en proceso de fabricación. Esta lógica representa un cambio fundamental respecto a los principios sobre los que reposaban la paz y la estabilidad del mundo, desde hace 58 años, aunque haya sido de manera imperfecta. Lo que me inquieta es que, si se adopta este principio, pudiera crear precedentes que multiplicarían el recurso a una fuerza unilateral y sin fundamento jurídico, con o sin ninguna justificación" (Le Monde, 23 de septiembre de 2003).

Juan Pablo II avala la tesis jurídica del Secretario General de Naciones Unidas, cuando afirmar que "El derecho internacional debe evitar que prevalezca la ley del más fuerte. Su objetivo esencial es reemplazar 'la fuerza material de las armas con la fuerza moral del derecho', sobre todo en los momentos en que se percibe la tentación de apelar al derecho de la fuerza más que a la fuerza del derecho". En este mensaje se introducen unas palabras de Juan Pablo II al cuerpo diplomático, acreditado ante la Santa Sede, el 13 enero 1997: "El derecho intemacional ha sido durante mucho tiempo un derecho de la guerra y de la paz. Creo que está llamado cada vez más a ser exclusivamente un derecho de la paz concebido en función de la justicia y de la solidaridad". Los juristas tienen un papel clave en este mensaje.

\section{Un nuevo ordenamiento internacional}

El objetivo central del mensaje del Papa es la urgencia de un nuevo orden intemacional como condición necesaria para el logro de la paz. En esta tarea se integran los juristas, en cuanto creadores e impulsores del derecho internacional; los jefes de las naciones, como promotores de la paz, y Naciones Unidas, como el centro moral que desarolla la conciencia de ser una "familia de naciones".

La primera tarea es educar en la legalidad. El derecho favorece la paz y así, desde los albores de la civilización, se ha ido formando un conjunto de normas, calificado como el jus gentium (el derecho de gentes). A partir del siglo XVI, juristas, filósofos y teólogos han elaborado los capítulos del derecho intemacional, basado en los fundamentos del derecho natural, principios universales, anteriores y superiores al derecho interno de los estados. Entre estos principios destaca el pacta sunt servanda, los acuerdos libremente firmados deben cumplirse, lo cual evita "la tentación de apelar al derecho de la fuerza más que a la fuerza del derecho".

Una breve mirada a nuestro orden internacional nos muestra, al menos, una trilogía de graves transgresiones a estos principios universales. He recordado antes que, contraviniendo los principios pactados en la Carta de Naciones Unidas, algunos jefes de Estado han librado guerras, en nombre de su propia autoridad, sin autorización del Consejo de Seguridad. Mirando el reverso de la medalla, cuántas veces los miembros del mismo Consejo se mostraron insensibles e inactivos ante las matanzas y genocidios, en varios rincones del mundo, sobre todo del mundo en desarrollo.

Una segunda y grave transgresión se ha cometido y se sigue cometiendo en las cumbres de la Organización Mundial del Comercio, donde los países industrializados imponen los pactos y las agendas de negociación. En la Organización Mundial del Comercio de Seattle, en 1999, los delegados de los países pobres y emergentes desconocían los temas de la agenda y no participaron en las negociaciones, sostenidas a puerta cerrada. "No sabemos qué decisiones se van a tomar y una vez más se nos pedirá suscribir un texto que ni tendremos tiempo de leer". La Organización Mundial del Comercio de Seattle fracasó, lo mismo que ha fracasado la reciente cumbre de Cancún, en septiembre de 2003, porque los gobiemos de Estados Unidos y Europa se negaron a cumplir los compromisos pactados dos años antes en Doha (Qatar), en noviembre de 2001 .

Las enormes asimetrías del comercio intemacional explican por qué el Premio Nobel de Eco- 
nomía, Joseph Stiglitz, ha dicho que "la teoría del libre comercio es un fraude intelectual". "El sistema de comercio global está con problemas; se predica el libre comercio como el evangelio en todas partes, pero parece que los países no hacen caso de su propio mensaje. Sus mercados permanecen cerrados a muchos de los productos de los países en desarrollo; subsidian a sus agricultores en forma masiva, lo que hace imposible que los países en desartollo puedan competir. El mensaje del G-7 parece ser: hagan lo que decimos, no lo que hacemos". El comercio intemacional es hoy un ejemplo histórico de "la paz violenta". El 20 de noviembre de 2003 tuvo lugar, en Miami, una reunión para reanudar las conversaciones sobre el área del libre comercio de las Américas (ALCA). A comienzos de septiembre, los obispos de Mercosur, Chile y Bolivia se reunieron en Montevideo y dieron a conocer un rico mensaje, en el cual exponen su oposición ante el área de libre comercio: "La excesiva desproporción de las capacidades competitivas entre nuestros países, algunos de ellos con economías muy fuertes y desarrolladas, otros muy débiles, y el desequilibrio de intereses y poderes, podrían traer consecuencias muy graves en relación a la identidad cultural, los puestos de trabajo y la misma subsistencia de las economías más frágiles. Más que una integración podría tratarse de un neocolonialismo con un impacto negativo sobre las comunidades locales". Sabemos que las asimetrías comerciales profundizan la pesada losa de la deuda externa, cuyo valor original, en 1982, se ha pagado cuatro veces, mientras que su monto se ha incrementado tres veces y media.

Una tercera transgresión del jus gentium (el derecho de gentes) es la de aquellos países que, tradicionalmente, se niegan a ratificar protocolos y convenciones que Naciones Unidas urge pactar para asegurar la paz, la salud y la vida de la humanidad. Hay gobiemos que se niegan a ratificar el protocolo de efecto invernadero de Kyoto, la convención sobre biodiversidad, sobre racismo, sobre minas antipersonas y, de manera especial, los estatutos de la Corte Penal Internacional. Al integrar estas tres transgresiones del jus gentium, descubrimos que el orden internacional está dominado por el triple unilateralismo político, económico y militar, que genera "la paz violenta", un gran obstáculo para la paz deseada.

Juan Pablo Il, nacido en Polonia, nación crucificada entre dos ladrones, Rusia y Alemania, recuerda cómo después de "los horrores y las terri-

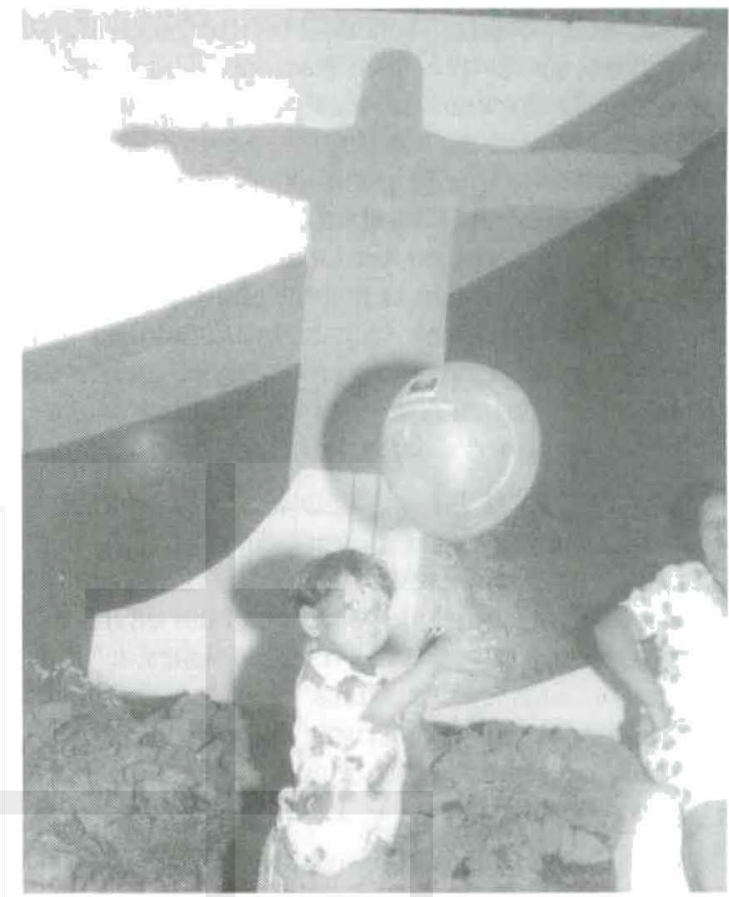

bles violaciones de la dignidad humana que causó la segunda guerra mundial", los gobiemos crearon una organización específica - - la Organización de las Naciones Unidas- con un Consejo de Seguridad, dotado de amplios poderes de acción. Como eje del sistema se puso "la prohibición del uso de la fuerza", según el conocido Capítulo VII de la Carta de Naciones Unidas.

Tenemos que agradecer los grandes aportes de Naciones Unidas a la educación, la salud, la infancia y los refugiados. Sin embargo, debo hacer mención especial a las cumbres mundiales sobre los grandes problemas como los derechos humanos, el desarrollo social, los derechos de la mujer, el alivio de la pobreza, el recalentamiento de la tierra, etc. Al ser tan importante, su actual Secretario General dijo en la Cumbre del Milenio: "tenemos que reinventar Naciones Unidas"; y en la reciente cumbre de septiembre de 2003 volvió a repetir: "tenemos que refundar Naciones Unidas". Algunos gobiemos y poderes, pese a esas cumbres, intercalan otros problemas e intereses, con lo cual ni la Asamblea General ni el Consejo de Seguridad cumplen, más bien incumplen, las funciones para las que fueron creadas.

Algunas de las preguntas e interrogantes que plantearon algunos delegados, en la $58^{a}$ Cumbre 
de Naciones Unidas, son un buen resumen de su naturaleza, ¿.para qué sirve Naciones Unidas si no logra que se respeten sus resoluciones? ¿Cuál es la representatividad del Consejo de Seguridad y cuáles los criterios que le permiten decidir el uso de la fuerza? ¿Hay que conservar “el derecho al veto”? ¿Habrá que pensar en trasladar la sede fuera de Nueva York? ¿Cuál es la responsabilidad de la comunidad intemacional, cuando un Estado no protege a sus ciudadanos? Los ciudadanos, ¿deben estar representados en Naciones Unidas? (Le Monde, 25 de septiembre de 2003).

Puesto que el Papa, y sus asesores, ponen la confianza en el "poder moral" de Naciones Unidas, agrego unos breves comentarios. Lamentablemente, hay gobiernos que se destacan por enviar a la vía muerta las convenciones o resoluciones de la organización. Sus "cascos azules" no tienen la misión de doblegar a estos gobiemos. El poder de Naciones Unidas es moral y, en algunos casos, la moral es un ser extraterrestre.

En las dos últimas cumbres, el Secretario General de Naciones Unidas y bastantes jefes de Estado afirmaron que el Consejo de Seguridad, el pasado y el actual, no son representativos de la estructura geográfica mundial, lo cual le resta legitimidad. Deben integrarse nuevos países y mencionan a Alemania, Japón y Brasil, en representación del tercer mundo. Después de la segunda guerra mundial y a lo largo de "la guerra fría", solo cinco países eran miembros permanentes de dicho Consejo: Estados Unidos, Rusia, China, Inglaterra y Francia. A lo largo del siglo $\mathrm{XX}$, estos países se han destacado por ser los cinco mayores exportadores de armas, lo cual no los cualifica para seguir siendo los cinco miembros permanentes con derecho a veto. Los otros diez miembros del actual Consejo son temporales.

Parece, pues, muy importante preguntar si hay que conservar "el derecho al veto". Una triste casualidad da la mejor respuesta. En plena cumbre de Naciones Unidas, el 14 de octubre de 2003, Siria, en nombre del grupo árabe, solicitó al Consejo de Seguridad condenar la construcción de "un muro de seguridad", en Cisjordania, que Israel había comenzado a levantar. El texto juzgaba que esa construcción "era ilegal de acuerdo a las normas del derecho intemacional" y solicitaba la oposición "a todas las actividades de colonización en los territorios ocupados y de todas las actividades que impliquen la confiscación de tierras y su anexión". Diez miembros del Consejo de Seguridad votaron que se detuviera la construcción de más de 150 kilómetros. Pero el embajador de Estados Unidos paró la resolución con su veto, porque el texto "no es equilibrado y no condenaba al terrorismo en términos explícitos". La condena avalada por diez miembros quedó así anulada "por un simple veto". La Asamblea General ha condenado la construcción del muro con una aplastante mayoría de 144 votos contra cuatro. Pero esta resolución solo tiene fuerza moral, y la moral no tiene fuerza.

Todo esto sucedía cuando el Papa y sus asesores redactaban este mensaje, donde dirigen una exhortación directa a Naciones Unidas. El Papa reconoce que Naciones Unidas - pese al incumplimiento de sus miembros - ha contribuido a promover notablemente el respeto de la dignidad humana, la libertad de los pueblos y la exigencia del desarrollo. Sin embargo, necesita una reforma para la consecución de sus objetivos estatutarios, porque "la humanidad, enfrentada a una etapa nueva y más difícil de su auténtico desarrollo, necesita hoy un grado superior de ordenamiento internacional [...] Es preciso que la Organización de Naciones Unidas se eleve cada vez más de la fría condición de institución de tipo administrativo a la de centro moral [...] por así decir, una 'familia de naciones'. ¿Serán estas palabras una directa alusión a lo sucedido dos meses antes?

En la última cumbre no se observa a una "familia de naciones". El Secretario General había presentado el estado de la situación mundial, las reformas que debían realizarse al interior de la institución y las amenazas duras y blandas, que aguardaban una respuesta colectiva. Lamentablemente, todos estos puntos de "agenda" (lo que se debe hacer) quedaron perdidos en el tintero. Las tres semanas que se prolongó la sesión se centraron en la invasión de Irak, los reveses y las dificultades de la ocupación, la necesidad de nuevas tropas y de mayor financiamiento para su estabilización política, la pacificación y la reconstrucción. ¿Cuál debía ser el papel de Naciones Unidas en este proceso? Aunque Lula da Silva dijo que "Naciones Unidas no ha sido creada para limpiar los escombros de conflictos que ella no pudo evitar", ahora se le exige un "apoyo condicionado" para tejer una Constitución y una paz "bajo el comando de las fuerzas de ocupación".

Sin tiempo ni espacio para detallar estos prolongados debates, el 16 de octubre salió una resolución confusa: "El Consejo de Seguridad de Na- 
ciones Unidas aprueba por unanimidad la operación norteamericana en Irak". ¿Dónde quedan los valores éticos y dónde queda el derecho internacional? Los expertos comentan que con el voto de la Resolución 1511, y a través de un esquema inédito, una fuerza de ocupación se convierte en multinacional y autorizada por Naciones Unidas. Este montaje parece ilegal, desde el punto de vista del derecho intemacional, pero el Consejo es por sí mismo "fuente de derecho" y nada se le puede objetar.

Al aprobar esa resolución, todos jugaron al "póquer del mentiroso". Estados Unidos no cedió en nada y Naciones Unidas tendría un papel secundario, bajo el mando de las fuerzas de ocupación, lo cual - sumado al asesinato de su representante Sergio Vieira de Mello- hizo que Annan retirara de Irak a todos los miembros de la organización. Los países que votaron a favor, a despecho del papel secundario de Naciones Unidas, proclamaron de forma abierta que no participarían ni con dinero ni con tropas en el esfuerzo de guerra. Otros delegados dieron algunas explicaciones mezquinas: "Nuestra opinión pública no se interesa tanto por Irak. No vamos a estar peleándonos eternamente con Estados Unidos". Un embajador reflexionó de manera más sensata: "Este es el suicidio del Consejo de Seguridad. Al reconocer que Estados Unidos puede ocupar un país y, además, conseguir el respaldo de la comunidad internacional, Naciones Unidas se declara a sí misma irrelevante”. ¿Querrá decir esto que también el derecho intemacional se ha vuelto irrelevante? Es necesario hacer un alto y una reflexión en el camino.

\section{La oportunidad del mensaje papal}

El Papa dice que estos últimos años han sido especialmente conflictivos: guerra y economía se hacen la guerra. En los foros económicos de Davos, los maestros del mundo dicen que la economía mundial está en declive. En Davos 2001, la agenda era recuperar el crecimiento y corregir las desigualdades. En Davos 2002, economía frágil e inseguridad: "la globalización de la ira se ha ido acelerando ante el rápido crecimiento de las desigualdades". La agenda de Davos 2003 es "recuperar la confianza". En los tres primeros meses de 2003 estalló la batalla diplomática dentro de Naciones Unidas entre los jefes de Estado que quieren agotar todos los medios pacíficos y quienes afirman tener derecho para iniciar una guerra preventiva, incluso sin autorización del Consejo de Seguridad. Esta guerra sigue alimentando una persistente división entre las naciones del hemisferio norte, que cohabitan en ambas riveras del Atlántico.

La guerra, que adquiere carácter de cruzada o de guerra santa por ambas partes, recrudece, en clave mayor, las respuestas violentas de ambos bandos, y los grandes medios de comunicación social desfiguran la verdad, al reservar el título de terroristas a los pueblos ocupados y de víctimas a los invasores. En este violento escenario crece lo que el Papa Ilama la plaga del terrorismo, que ha producido masacres atroces, y, por el otro lado, se desarrolla la xenofobia, conducta cercana al terrorismo. Naciones Unidas no es "una familia de naciones" y el derecho intemacional no halla dónde reposar su pie.

Los pueblos del tercer mundo entran por otra puerta en la misma vorágine. Se les había dicho que la cumbre de Cancún sería "la Organización Mundial del Comercio del desarrollo", pero una vez más sus esperanzas y sus problemas más graves quedaron fallidas. También la Organización Mundial del Comercio ha quedado desprestigiada. En la reunión del área de libre comercio de las Américas de Miami, el 20 noviembre 2003, se acordó un área de libre comercio "de dos velocidades", ante la resistencia del Mercosur. El año 2004 amenaza ser un año de serias tensiones comerciales.

Ahora podemos entender por qué el mensaje del Papa se dirige a los cuatro destinatarios, donde cada uno tiene un papel relevante. A nosotros nos toca, eminentemente, el de los educadores, educar "con-ciencia", en el camino de la comprensión y del diálogo. En esta tarea no estamos solos. Desde enero de 2001 se viene reuniendo, en el foro social mundial de Porto Alegre, un creciente número de manifestantes pacíficos (20 mil, $50 \mathrm{mil}, 100 \mathrm{mil}$ personas, en enero de 2003). Este año lo harán en India. Desean pasar de la protesta a la propuesta para crear una "globalización desde abajo", donde quepa toda la humanidad. También ellos nos dan esperanza. Su lema es: "otro mundo mejor es posible".

Francisco J. Ibisate Catedrático del Departamento de Economía de la UCA 